\title{
Aluminum-doped zinc oxide films grown by atomic layer deposition for transparent electrode applications
}

\author{
G. Luka $\cdot$ T. A. Krajewski $\cdot$ B. S. Witkowski • \\ G. Wisz • I. S. Virt • E. Guziewicz • \\ M. Godlewski
}

Received: 4 February 2011/ Accepted: 31 March 2011/Published online: 19 April 2011

(C) The Author(s) 2011. This article is published with open access at Springerlink.com

\begin{abstract}
We obtained zinc oxide films doped with aluminum using atomic layer deposition (ALD). Their morphology, growth mode, optical and electrical properties are studied. Al content dependence is analyzed. Carrier scattering mechanisms in $\mathrm{ZnO}: \mathrm{Al}$ (AZO) films are investigated from conductivity versus temperature measurements. We also discuss how the film thickness affects its resistivity and optical transmission. The obtained film resistivities, i.e. $7 \times 10^{-4} \Omega \mathrm{cm}$, belong to the lowest reported so far for transparent $\mathrm{ZnO}$ :Al films grown by the ALD method.
\end{abstract}

\section{Introduction}

The further progress in developing and commercialization of new generations of optoelectronic and photovoltaic devices is limited by necessity of fabrication of low-cost thin films acting as transparent conductive (TC) electrodes. These films should replace so far conventionally used indium tin oxide (ITO) layers, which are too expensive.

\footnotetext{
G. Luka $(\bowtie) \cdot$ T. A. Krajewski · B. S. Witkowski ·

E. Guziewicz · M. Godlewski

Institute of Physics, Polish Academy of Sciences, Warsaw,

Poland

e-mail: gluka@ifpan.edu.pl

G. Wisz · I. S. Virt

University of Rzeszow, Rzeszow, Poland

I. S. Virt

Drogobych Pedagogical University, Drogobych, Ukraine

M. Godlewski

Department of Mathematics and Natural Sciences, College

of Science, Cardinal Stefan Wyszynski University,

Warsaw, Poland
}

Among the variety of materials tested for the TC applications, zinc oxide is one of the most prospective ones not only because of its low cost, simplicity of deposition, but also due to its unique optical properties, such as high transparency even when heavily doped [1, 2].

Among various deposition methods, magnetron sputtering is the one that enables to obtain $\mathrm{ZnO}$ films with the lowest resistivity $\left(2 \times 10^{-4} \Omega \mathrm{cm}\right)$ for films doped with $\mathrm{Al}$. This resistivity is comparable to that of ITO films, for which resistivities of $1 \times 10^{-4} \Omega \mathrm{cm}$ were reported [3].

In this report, we used atomic layer deposition to obtain zinc oxide films doped with aluminum. The atomic layer deposition (ALD) technique is a kind of chemical vapor deposition (CVD) method, but there are two features that distinguish the ALD process from the CVD one. Firstly, precursors are sequentially introduced to the growth chamber, and each precursor dose is separated from another by purging the chamber with a neutral gas $\left(\mathrm{N}_{2}\right.$, for example). Secondly, each precursor is introduced into the chamber in sufficient amount to totally cover substrate surface. These two features enable uniform film deposition on very large area substrates, even with a size of a few $\mathrm{m}^{2}$. Furthermore, ALD can be used for conformal and dense film deposition onto very complex substrate surfaces [4]. This is an advantageous property. We cannot use sputtering to cover uniformly 3D-like structures, studied now for the photovoltaic applications [5]. This makes the ALD method very promising and competitive. Unfortunately, the lowest resistivities of $\mathrm{Al}$-doped $\mathrm{ZnO}$ transparent films grown by the ALD reported till now were about $1 \times 10^{-3} \Omega[6,7]$. They are rather high, larger than those reported not only for ITO films, but also for $\mathrm{ZnO}$ :Al ones obtained by sputtering [8]. Even though for many applications very low resistivity values are not required, e.g. for organic electronics, further progress is very urgent. Regarding organic electronics, we 
have demonstrated recently that using an undoped (i.e. not intentionally doped) $\mathrm{ZnO}$ film as a transparent anode with resistivity of $1 \times 10^{-3} \Omega \mathrm{cm}$ and sheet resistance of $50 \Omega / \square$ was optimal to ensure a good performance of an organic light emitting diode (OLED) [9].

Here, we investigate film morphology, structure and mechanisms affecting electrical conductivity of ALDdeposited $\mathrm{ZnO}$ :Al films with various $\mathrm{Al}$ contents. At first, for undoped films we optimized growth parameters to obtain films with resistivities in the order of $10^{-3} \Omega \mathrm{cm}$ [10]. These films were highly conductive, due to the presence of native point defects like interstitial zinc [11]. The next step was to optimize their doping with Al. We managed to decrease the film resistivity below $9 \times 10^{-4} \Omega \mathrm{cm}$, while maintaining high optical transmission. These are the best results achieved with the ALD method.

\section{Experimental}

Zinc oxide films were grown by the ALD method from diethylzinc (DEZ) and water vapor as zinc and oxygen precursors, respectively. For doping with aluminum, trimethylaluminum (TMA) was used. The films were grown in Savannah-100 ALD reactor (Cambridge NanoTech). The process pressure was $\sim 10^{-1}$ mbar, the $\mathrm{N}_{2}$ purging gas flow rate was $20 \mathrm{sccm}$, and the growth temperature was $200^{\circ} \mathrm{C}$.

To obtain AZO films with different $\mathrm{Al}$ contents, we applied one TMA $+\mathrm{H}_{2} \mathrm{O}$ cycle separated by the given number $(j)$ of $\mathrm{DEZ}+\mathrm{H}_{2} \mathrm{O}$ ones: $[i \times(\mathrm{TMA}+$ $\left.\mathrm{H}_{2} \mathrm{O}\right)+j \times\left(\right.$ DEZ $\left.\left.+\mathrm{H}_{2} \mathrm{O}\right)\right] \times k$, where $i=1$. The total number of cycles, $c$, was: $c=\left(i_{\mathrm{Al} 2 \mathrm{O} 3}+j_{\mathrm{ZnO}}\right) \times k$.

The strategy to obtain films with the lowest resistivity was as follows. Firstly, we adjusted $k$ (and $c$ ) to obtain films with the thicknesses of $200 \mathrm{~nm}$. Our next step was to apply different number of cycles to obtain films with different thicknesses, but with optimal number of $j$, i.e. with the Al content under which $200 \mathrm{~nm}$-thick films have the lowest resistivities.

Note that we always followed the $\mathrm{Al}_{2} \mathrm{O}_{3}$ cycle by the $\mathrm{ZnO}$ cycles. The corresponding precursor pulse and purge times were kept constant for all deposited films.

The films were grown on glass and Si substrates. Films grown on Si were used to check their thickness (and calculate the growth rates) and to investigate the growth mode (by cross-section images). Other investigations, i.e. surface morphology, chemical composition, optical and electrical measurements were carried on AZO films grown on glass substrates.

The film thickness was measured by Micropack Nanocalc 2000 reflectometer. Whereas, their morphology, crosssection images and chemical composition were obtained using Hitachi SU-70 scanning electron microscope (SEM). The $\mathrm{Al}$ contents in AZO films were determined by electron dispersive X-ray (EDX) method and are given in atomic percents.

Electrical parameters of the films were studied first at room temperature. The Hall effect measurements were carried on in the Van der Pauw mode using the RH2035 PhysTech GmbH system with a magnet field $\mathrm{B}=0.4 \mathrm{~T}$. Resistivity versus temperature measurements were performed at $77-300 \mathrm{~K}$ range.

Optical transmission spectra were measured in the wavelength range of 300-1,100 nm using Solar CM2203 spectrometer.

\section{Results}

Zinc oxide films, while doped with aluminum, are grown at slightly lower growth rates comparing to undoped films, as is shown in Fig. 1. This suggests that the growth rate is controlled by surface reconstruction mechanisms [12]. In fact, the decrease of AZO lattice constants (obtained from the X-ray diffraction data, not shown here) with the increase of Al content [13] supports this statement. Similar observation of the growth rate controlled by the surface reconstruction was reported for CdTe grown by the ALD [12].

Surface morphology and cross-section images of AZO samples are presented in Figs. 2 and 3, respectively. The increase of the aluminum content leads to decrease of the mean grain size and decrease of the surface roughness. The low surface roughness is very desirable in device applications. We observe the columnar type of growth of AZO films. This is observed especially for the aluminum content of 0.8 and 1.4 at.\%. For 5 at. $\%$ and 7.8 at.\% of Al,

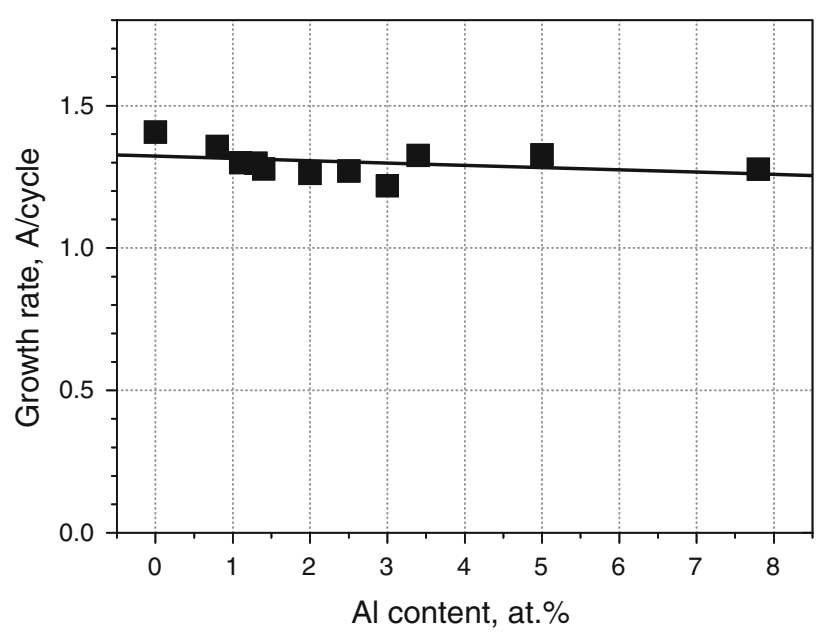

Fig. 1 Growth rate versus aluminum content in AZO films 

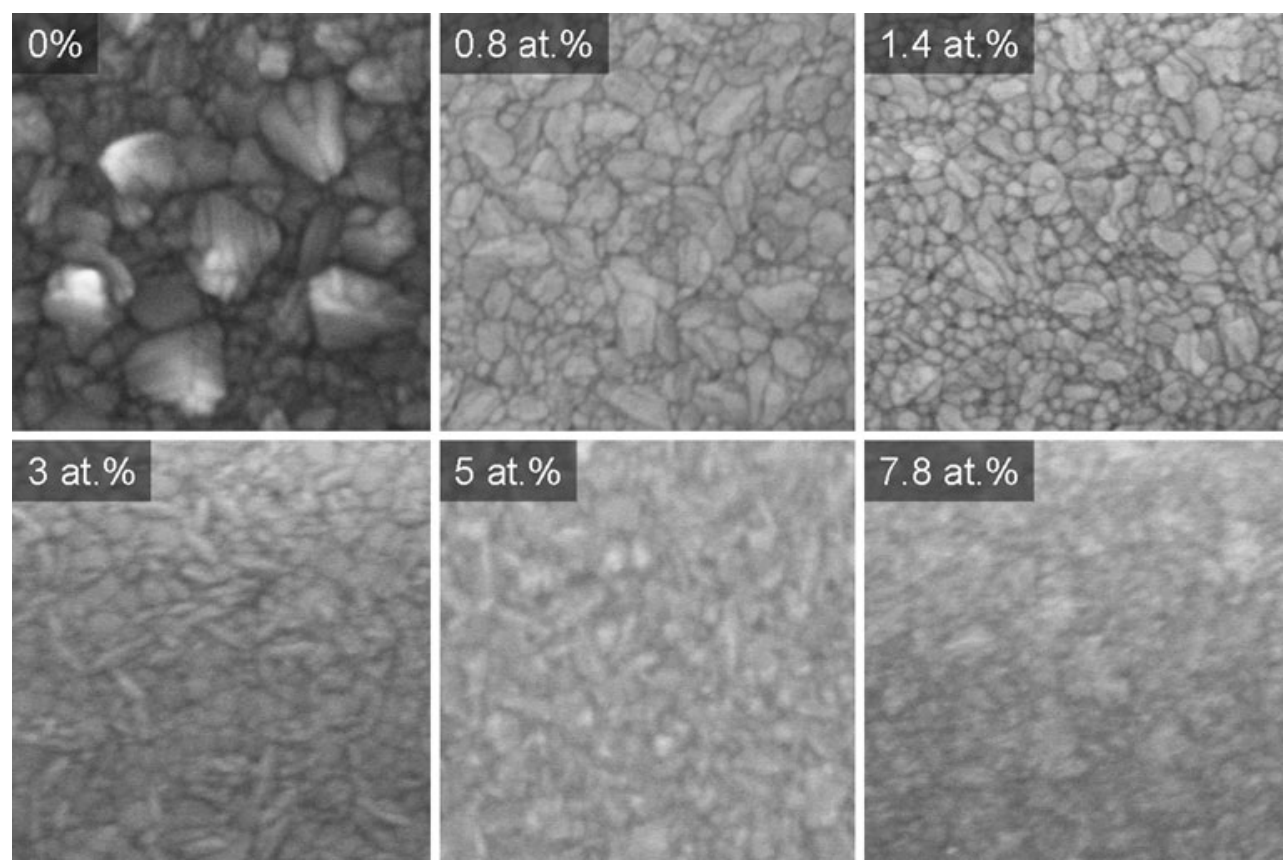

Fig. 2 Surface morphology of AZO/glass samples with different at.\% of Al. Each image size is $500 \times 500 \mathrm{~nm}$
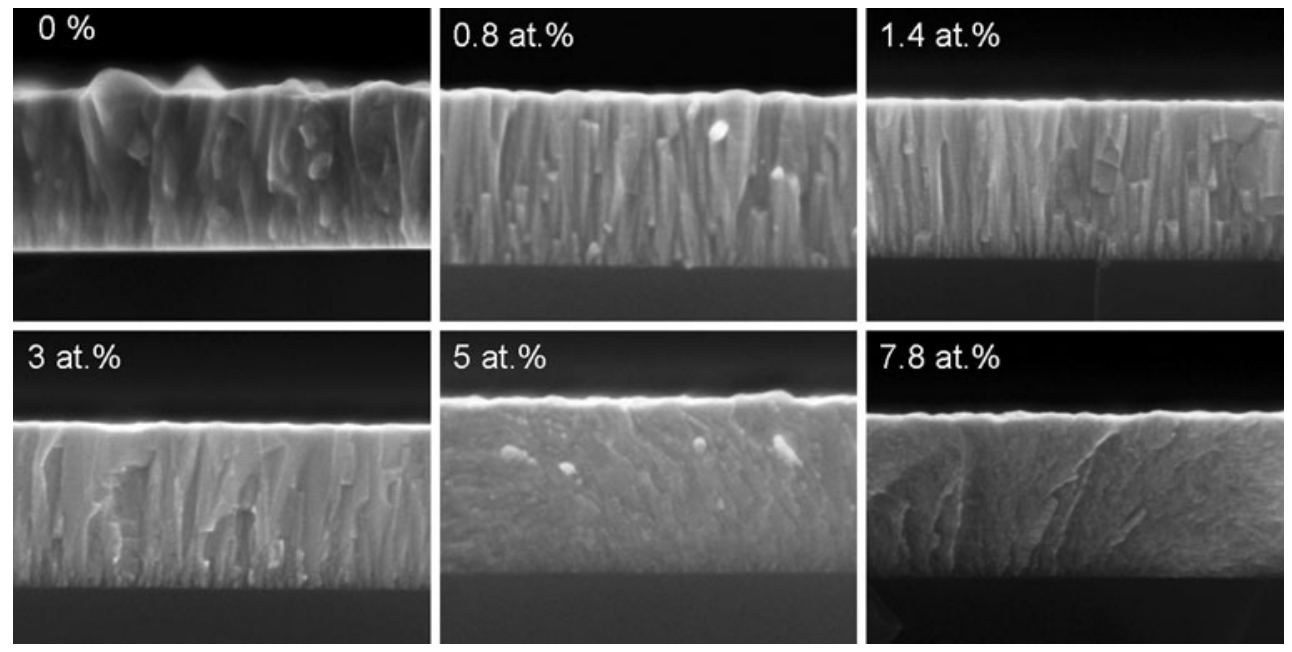

Fig. 3 Cross-section images of AZO/Si samples with different at.\% of Al. The film thicknesses are $200 \mathrm{~nm}$

a columnar-like growth is no longer dominant and an amorphous-like structure appears.

Introduction of aluminum causes the decrease of film resistivity, as shown in Fig. 4a. Even undoped films have very low resistivity, i.e. $4 \times 10^{-3} \Omega \mathrm{cm}$. This is due to native defects, mainly zinc interstitials $[9,14]$ which can act as very efficient donors in $\mathrm{ZnO}$ [3]. The resistivity of the films is the lowest for $\mathrm{Al}$ content of 3 at.\%, and is $8 \times 10^{-4} \Omega \mathrm{cm}$. The electron concentration increases from $6 \times 10^{19} \mathrm{~cm}^{-3}$ (for undoped films) to $6 \times 10^{20} \mathrm{~cm}^{-3}$ (for the films with 3.4 at.\% of Al). Then, it decreases slowly for samples with higher $\mathrm{Al}$ contents. This decrease of the carrier concentration can be explained by compensation effects, i.e. by native defect formation. The most probable intrinsic defects formed while doping with $\mathrm{Al}$ are zinc vacancies since their formation energy is relatively low [15]. This assumption is supported by the EDS data, presented in Fig. 4d. When the $\mathrm{Al}$ content is higher than 2 at.\%, decrease of $\mathrm{Zn}$ content is observed. Comparing Fig. $4 \mathrm{~b}$ and $\mathrm{d}$, we conclude that the formation of zinc vacancies is associated with decrease of the electron mobility, which is mainly due to the scattering at ionized impurities [16]. It can also be associated with the decrease of the mean grain size (Fig. 3). The influence of grain 
(a)

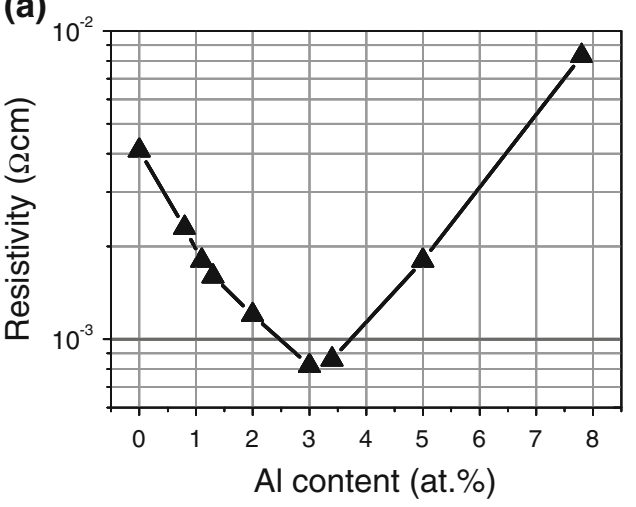

(c)

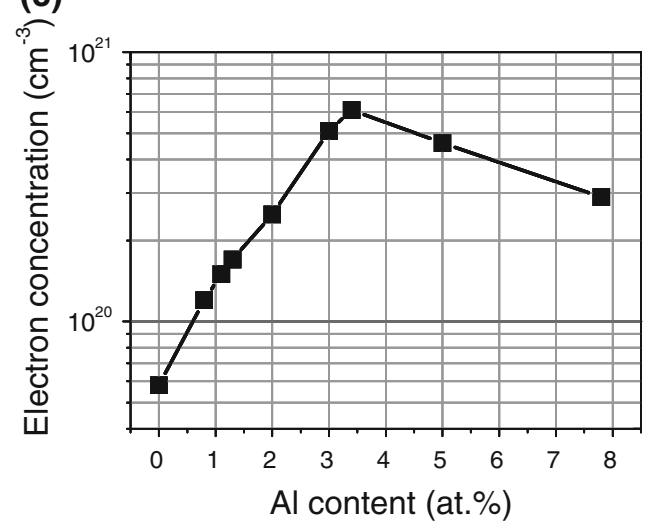

(b)

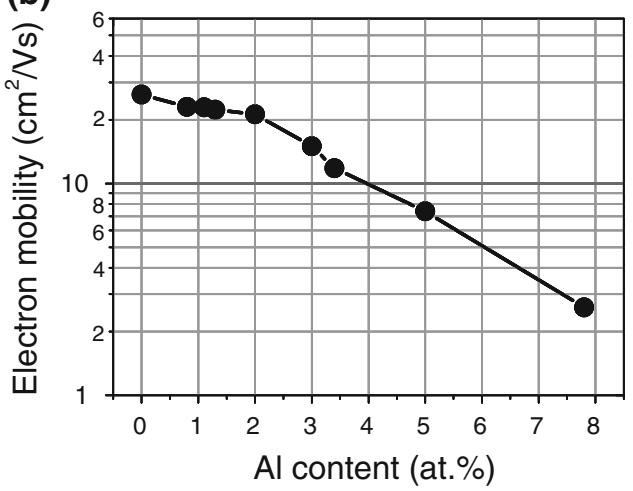

(d)

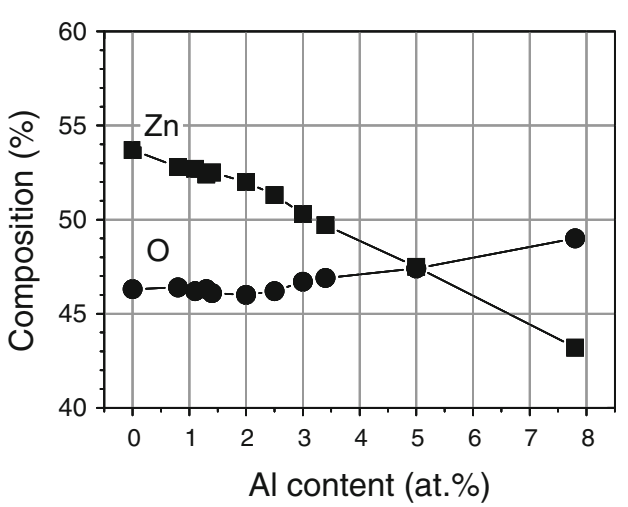

Fig. 4 a-c Electrical parameters and $\mathbf{d}$ chemical composition of AZO films

boundaries on the electrical properties of AZO films was investigated. We performed temperature-dependent conductivity measurements. Figure 5 shows the data in $\ln (\sigma)(1,000 / T)$ scale. From these data, it is seen that all the films exhibit metallic conductivity at room temperature. In this temperature region, conductivity decreases with the increase of temperature.

The barrier heights, $\Phi_{B}$, at grain boundaries can be estimated using the formula [3]:

$\mu(T) \sim \exp \left(-\Phi_{B} / k_{B} T\right)$

where $\mu$ is carrier mobility, $k_{B}$ is the Boltzmann constant and $T$ is temperature. For high electron concentrations $n$ in $\mathrm{ZnO}$ $\left(n>10^{18} \mathrm{~cm}^{-3}\right), n$ does not depend on measurement temperature $[17,18]$. So, we can assume that film conductivity is proportional to the carrier mobility and thus to $\exp \left(-\Phi_{B} / k_{B} T\right)$. The calculated values of $\Phi_{B}$ are very low indicating that tunneling through the grain barriers dominates over the thermionic emission processes, especially with the increase of electron concentration. For $\mathrm{Al}$ contents of $0.8-3$ at. $\%$ and at temperatures below $160 \mathrm{~K}$ we observe that $\sigma(T)=$ const. It can be attributed to the scattering at the neutral impurities [19]. The temperature range, at which this scattering mechanism is dominant, increases with the increase of free electron concentration. For 5 at.\% of $\mathrm{Al}$, such dependence is not observed. For films with $0.8-3$ at.\% of Al, we can relate the $\ln (\sigma)$ versus $T^{-1}$ dependence below and above this temperature range, to ionized impurity and phonon scattering effects, respectively.

All the films are transparent, as is shown in Fig. 6a. The average transmission in the visible range is $\sim 90 \%$. The absorption edge shifts toward higher energies with the increase of $\mathrm{Al}$ content. From these data, we calculated optical band-gap energies, $E_{g}^{\text {opt }}$, using the relation [20]

$(\alpha \cdot h v)^{2} \sim\left(h v-E_{g}^{o p t}\right)$

where $\alpha$ is absorption coefficient and $h v$ is photon energy. Figure $6 \mathrm{~b}$ presents the optical energy gap versus aluminum content in AZO films. The value of $E_{g}^{\text {opt }}$ increases with the increase of $\mathrm{Al}$ composition. From $E_{g}^{\text {opt }}$ versus $n^{2 / 3}$ data (the inset of Fig. 6b), we observe the weak dependence of $E_{g}^{o p t}$ on $n^{2 / 3}$ (for the $\mathrm{Al}$ contents up to 1.1 at.\%) followed by linear behavior of this dependence for higher $\mathrm{Al}$ contents indicating a Burstein-Moss effect, i.e. the movement of the Fermi level due to filling of the lowest states of conduction band caused by $\mathrm{Al}$ doping. However, for $\mathrm{Al}$ contents of 3 at $\%$ and more, the decrease of $n$ together with the further increase of $E_{g}^{o p t}$ is observed. We speculate, that the fall of the free electron concentration can be due to the formation 

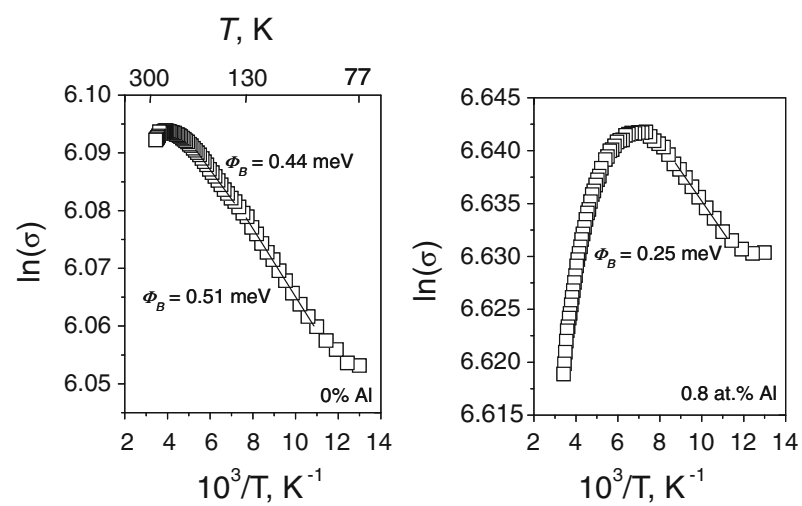

EDS data (Fig. 4d), we presume that already undoped $\mathrm{ZnO}$ films contain some amounts of Frenkel pairs, namely zinc interstitials and zinc vacancies. It is also possible that oxygen interstitials, instead of zinc vacancies, are formed. Based on present results we cannot reject such possibility.

Next, we investigated how the resistivity of AZO films depends on the film thickness, $t$. We used growth conditions, under which $200 \mathrm{~nm}$-thick films have the lowest resistivities, i.e. for 3 at.\% of $\mathrm{Al}$ content in the films. Table 1. presents electrical parameters of the films with the thicknesses of 130, 200, 300, and 1,000 $\mathrm{nm}$. The electron concentration
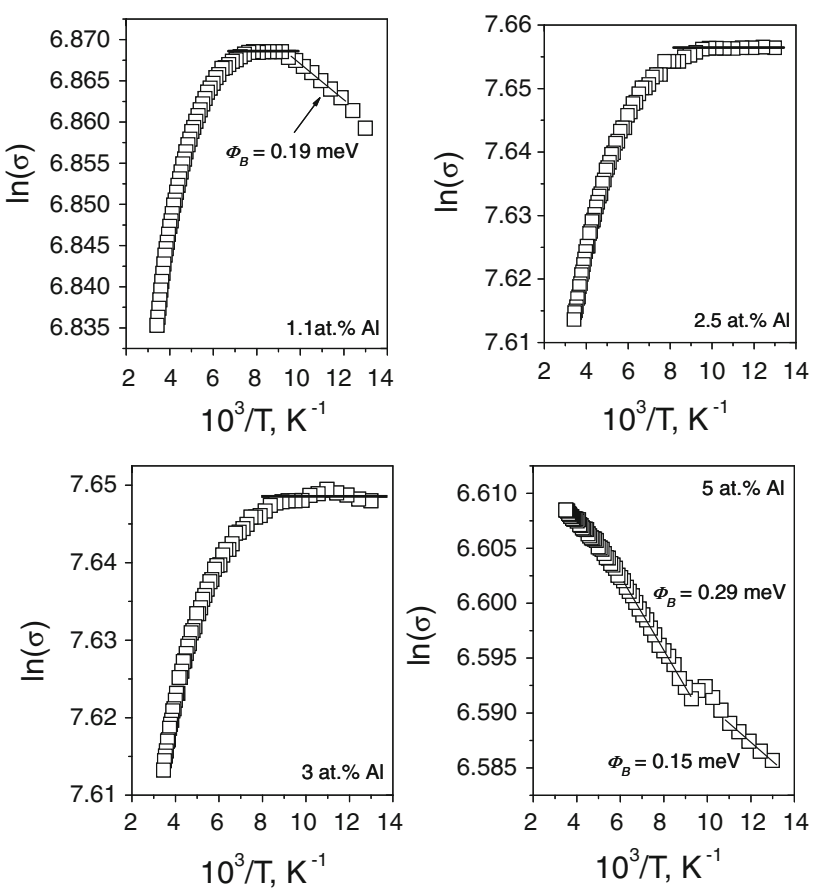

Fig. 5 Conductivity versus temperature data for AZO films

of zinc vacancies. Absorption due to excitation from zinc vacancy levels to conduction band likely explains rather low values of $E_{g}^{o p t}$ for undoped films $(\approx 3 \mathrm{eV})$ comparing to energy gap of $\mathrm{ZnO}$ crystals $(\sim 3.4 \mathrm{eV}$ [21]). From the increases with the film thickness up to $5 \times 10^{20} \mathrm{~cm}^{-3}$ (for $t=200 \mathrm{~nm}$ ). Then it decreases slightly for thicker films. In turn, electron mobilities increase with the film thickness. The improvement of the structural properties of the films results in lower barriers at grain boundaries and in larger grain sizes in the upper parts of the films [22]. The lowest resistivity obtained was $7 \times 10^{-4} \Omega \mathrm{cm}$ for $1 \mu \mathrm{m}$-thick AZO films.

Figure 7 shows optical transmission of the films with different thicknesses. Also in this case all the films are highly transparent. The average optical transmission for all the films is $\approx 90 \%$. For the sample with a thickness of $130 \mathrm{~nm}$, the transmission reaches a value of $100 \%$ for the wavelength of $550 \mathrm{~nm}$. This is only an interference effect and also in this case the average transmission is $\approx 90 \%$. Note that even $1 \mu \mathrm{m}$-thick AZO films are highly transparent.

\section{Conclusions}

We used ALD method to obtain two series of AZO films, with different aluminum contents and with different film thicknesses, respectively. The films posses resistivities as low as $7 \times 10^{-4} \Omega \mathrm{cm}$ and optical transmission in the order of $90 \%$ in the visible range, even for $1 \mu \mathrm{m}$-thick AZO films. The obtained resistivities are the lowest reported so far for transparent AZO films grown by the ALD method.

Fig. 6 a Optical transmission and absorption (inset) of AZO films. b Optical band-gap energy versus aluminum content. The inset shows $E_{g}^{\text {opt }}$ versus $n^{2 / 3}$ dependence (a)

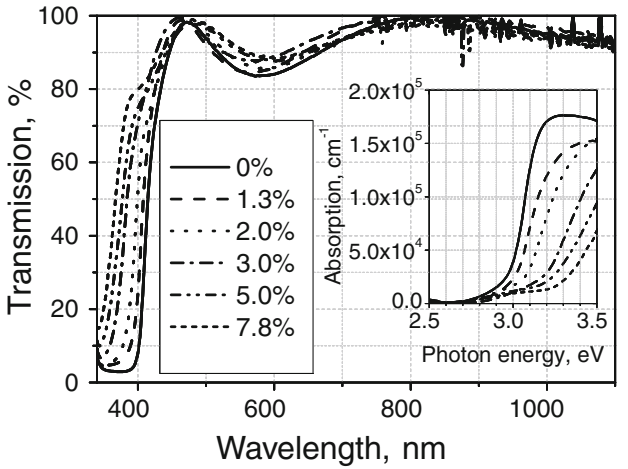

(b)

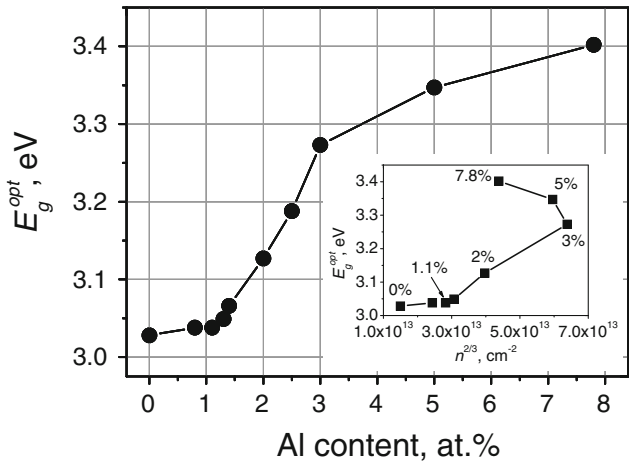


Table 1 Electrical parameters of AZO films depending on their thicknesses

\begin{tabular}{llllcr}
\hline Sample no. & $t(\mathrm{~nm})$ & $n\left(\mathrm{~cm}^{-3}\right)$ & $\mu\left(\mathrm{cm}^{2} / \mathrm{Vs}\right)$ & $\rho(\Omega \mathrm{cm})$ & $R_{\text {sh }}(\Omega / \square)$ \\
\hline 1 & $130 \pm 10 \mathrm{~nm}$ & $3.6 \times 10^{20} \pm 7 \%$ & $15.0 \pm 9 \%$ & $1.2 \times 10^{-3}$ \\
2 & 200 & $5.1 \times 10^{20}$ & 15.0 & $8.2 \times 10^{-4}$ \\
3 & 306 & $4.9 \times 10^{20}$ & 16.7 & $7.7 .3 \times 10^{-4}$ & 25.2 \\
4 & 1,060 & $4.1 \times 10^{20}$ & 21.8 & $7.1 \times 10^{-4}$ \\
\hline
\end{tabular}

$t$ film thickness, $n$ electron concentration, $\mu$ electron mobility, $\rho$ film resistivity, $R_{s h}$ sheet resistance

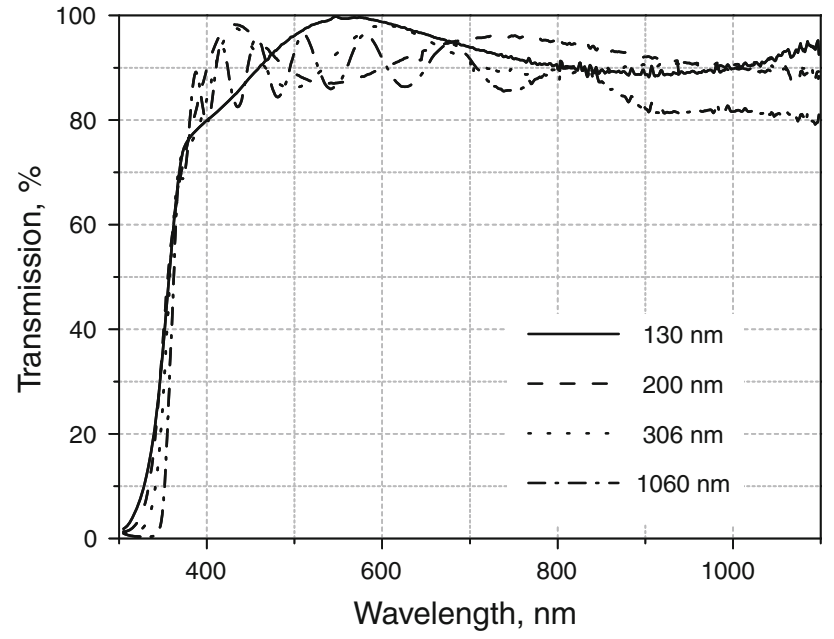

Fig. 7 Optical transmission data for AZO films with different film thicknesses

Acknowledgments The research was partially supported by the European Union within European Regional Development Fund, through grant Innovative Economy (POIG.01.01.02-00-008/08).

Open Access This article is distributed under the terms of the Creative Commons Attribution Noncommercial License which permits any noncommercial use, distribution, and reproduction in any medium, provided the original author(s) and source are credited.

\section{References}

1. C.G. Granqvist, Sol Energy Mater. Sol Cells 91, 1529 (2007)

2. M. Godlewski, E. Guziewicz, G. Łuka, T. Krajewski, M. Łukasiewicz, Ł. Wachnicki, A. Wachnicka, K. Kopalko, A. Sarem, B. Dalati, Thin Solid Films 518, 1145 (2009)

3. K. Ellmer, A. Klein, B. Rech (eds.), Transparent conductive zinc oxide (Springer, Heidelberg, 2008)

4. P.M. Martin, Handbook of deposition technologies for films and coatings, third edition: science, applications and technology (Elsevier, Amsterdam, 2010)
5. B. Myers, M. Bernardi, J.C. Grossman, Appl. Phys. Lett. 96, 071902 (2010)

6. V. Lujala, J. Skarp, M. Tammenmaa, T. Suntola, Appl. Surf. Sci. 82-83, 34 (1994)

7. S.H. Ko Park, J.I. Lee, C.S. Hwang, H.Y. Chu, Jpn. J. Appl. Phys. Part 2 44, L242 (2005)

8. K. Ellmer, J. Phys D: Appl. Phys. 34, 3097 (2001)

9. G. Luka, P. Stakhira, V. Cherpak, D. Volynyuk, Z. Hotra, M. Godlewski, E. Guziewicz, B. Witkowski, W. Paszkowicz, A. Kostruba, J. Appl. Phys. 108, 064518 (2010)

10. G. Luka, T. Krajewski, L. Wachnicki, B. Witkowski, E. Lusakowska, W. Paszkowicz, E. Guziewicz, M. Godlewski, Phys. Status Solidi A 207, 1568 (2010)

11. T.A. Krajewski, G. Luka, L. Wachnicki, R. Jakiela, B. Witkowski, E. Guziewicz, M. Godlewski, N. Huby, G. Tallarida, Opt. Appl. 39, 865 (2009)

12. T. Suntola, in Handbook of crystal growth, Part 3b-growth mechanisms and dynamics, ed. by D.T.J. Hurle (Elsevier, Amsterdam, 1994), pp. 605-663

13. Luka G, Wachnicki L, Witkowski BS, Krajewski TA, Jakiela R, Guziewicz E, Godlewski M, Mater. Sci. Eng. B (2011). doi: 10.1016/j.mseb.2010.11.014

14. T.A. Krajewski, G. Luka, L. Wachnicki, R. Jakiela, B. Witkowski, E. Guziewicz, M. Godlewski, N. Huby, G. Tallarida, Opt. Appl. 39, 865 (2009)

15. M. Willander, O. Nur, J.R. Sadaf, M.I. Qadir, S. Zaman, A. Zainelabdin, N. Bano, I. Hussain, Materials 3, 2643 (2010)

16. Z.C. Jin, I. Hamberg, C.G. Granqvist, J. Appl. Phys. 64, 5117 (1988)

17. A.P. Roth, J.B. Webb, D.F. Williams, Phys. Rev. B 25, 7836 (1982)

18. T.A. Krajewski, K. Dybko, G. Luka, L. Wachnicki, B.S. Witkowski, A. Duzynska, K. Kopalko, E. Lusakowska, B.J. Kowalski, M. Godlewski, E. Guziewicz, Phys. Status Solidi B 247, 1653 (2010)

19. K. Ellmer, R. Mientus, Thin Solid Films 516, 5829 (2008)

20. P.Y. Yu, M. Cardona, Fundamentals of semiconductors. Physics and materials properties (Springer, Berlin, 2005)

21. Ü. Özgür, Y.I. Alivov, C. Liu, A. Teke, M.A. Reshchikov, S. Doğan, V. Avrutin, S.-J. Cho, H. Morkoç, J. Appl. Phys. 98, 041301 (2005)

22. S. Hayamizu, H. Tabata, H. Tanaka, T. Kawai, J. Appl. Phys. 80, 787 (1996) 